\title{
DESIGN AND FABRICATION OF A COMPACT MICROSTRIP TRIPLEXER FOR WIMAX AND WIRELESS APPLICATIONS
}

\author{
Abbas Rezaei ${ }^{*}$ - Salah I. Yahya ${ }^{2,3}$ - Leila Noori ${ }^{4}$ - Mohd Haizal Jamaluddin ${ }^{5}$ \\ ${ }^{1}$ Department of Electrical Engineering, Kermanshah University of Technology, Kermanshah, Iran \\ ${ }^{2}$ Department of Communication and Computer Engineering, Cihan University-Erbil, Erbil, Kurdistan Region, Iraq \\ ${ }^{3}$ Department of Software Engineering, Faculty of Engineering, Koya University, Koya KOY45, Kurdistan Region, Iraq \\ ${ }^{4}$ Department of Electrical and Electronics Engineering, Shiraz University of Technology, Shiraz, Iran \\ ${ }^{5}$ Wireless Communication Centre, School of Electrical Engineering, Universiti Teknologi Malaysia, Johor, Malaysia
}

\begin{tabular}{l}
\hline ARTICLE INFO \\
\hline Article history: \\
Received: 25.5 .2019$. \\
Received in revised form: 22.10 .2019$. \\
Accepted: 24.10 .2019$. \\
\hline Keywords: \\
Compact \\
Microstrip \\
Resonator \\
Triplexer \\
WiMAX \\
Wireless \\
\hline DOI: http://doi.org/10.30765/er.1467 \\
\hline
\end{tabular}

\begin{abstract}
:
A novel structure to design a microstrip triplexer for wireless and WiMAX applications is presented. To obtain a compact microstrip layout, step impedance resonators and coupled lines are used. The introduced triplexer has a size of $0.35 \lambda_{g} \times 0.26 \lambda_{g}$, where $\lambda_{g}$ is calculated at $2.3 \mathrm{GHz}$. Also, the obtained insertion losses are $0.78 \mathrm{~dB}, 1.1 \mathrm{~dB}$ and $0.62 \mathrm{~dB}$ at $2.3 \mathrm{GHz}, 3.2 \mathrm{GHz}$ and $3.6 \mathrm{GHz}$, respectively. The $\mathrm{LC}$ model of the presented resonator is investigated to tune three resonance frequencies by calculating numerical values of inductors and capacitors. Finally, the designed triplexer is simulated and measured.
\end{abstract}

\section{Introduction}

Recently, microstrip triplexers have been widely used in modern communication systems for separating signals that are close together, as well as selecting the desired frequency ranges in crowded frequency bands. Having low insertion losses and compact size are important factors for designing a high-performance microstrip triplexer. In [1], a triplexer composed of a dual-band bandpass filter and a lowpass filter is realized by using microstrip matching cells, stepped-impedance, parallel coupled lines, hairpin and openloop resonator. It has a low insertion losses, weak frequency selectivity and large size. Most of the previous works could not reduce the insertion loss [2-11]. Also, some of the previous designs have large sizes [4-7]. In [3], a microstrip triplexer constructed by hairpins is presented. To design a triplexer in [4], step impedance structures are used as matching networks to integrate main resonators so that a high selectivity response is achieved. Coupled open-loop resonators and coupled lines are utilized to obtain a microstrip triplexer in [12]. It has good performances in terms of high selectivity and isolation. Another diplexer is constructed in [5] by using open-loop resonators for mobile communication systems at $1.8 \mathrm{GHz}$, WiMAX applications at $3.2 \mathrm{GHz}$ and C-band applications at $4.4 \mathrm{GHz}$. In [6], a high isolation microstrip triplexer is obtained using parallelcoupled lines and U-shape structures. In [7], a microstrip triplexer with wide fractional bandwidths is presented using a star junction structure. In [8], asymmetric split-ring resonators are utilized to create a compact microstrip triplexer with three close channels $(2.15,2.95$ and $3.80 \mathrm{GHz})$. In [10], a low pass-band pass triplexer is demonstrated in a T-shape, U-shape and hairpin resonators. In [9], the third order parallelcoupled band pass filters are integrated to introduce a wide stop band triplexer. In [11], a compact triplexer is designed by using coupled lines and radial structures. In $[12,13]$, two microstrip triplexers are achieved to improve the insertion loss. In [14], a fully integrated triplexer with a large implementation area is proposed for multi-band ultra-wideband applications.

A new microstrip triplexer is designed in [15] based on the properties of coupled lines, steps, and spiral cells to operate at $2.67 \mathrm{GHz}$ for $4 \mathrm{G} \mathrm{LTE}$ and at $3.1 \mathrm{GHz}$ and $3.43 \mathrm{GHz}$ for WiMAX. A microstrip triplexer

\footnotetext{
* Corresponding author

E-mail address: a.rezaee@kut.ac.ir
} 
with wide stop band is proposed in [16] using uniform impedance and common crossed resonators. In [17], a novel microstrip triplexer is proposed for wireless applications, which consists of spiral and patch cells. In [18], a novel microstrip triplexer is designed using split ring resonators for LTE application. In [19], two multiband microstrip multiplexers are proposed using distributed coupling method. They consist of asymmetric stepped-impedance resonators, a distributed coupling feeding line. In [20], a double-stub-loaded resonator is utilized to design a microstrip triplexer. In [21], uniform impedance and common crossed resonators are utilized to design a novel microstrip triplexer.

The purpose of this paper is designing a novel compact microstrip triplexer with a simple structure to operate at the frequencies of $2.3 \mathrm{GHz}, 3.2 \mathrm{GHz}$ and $3.6 \mathrm{GHz}$ for WiMAX and wireless applications. For this purpose, a microstrip resonator is proposed and its $L C$ equivalent model is portrayed. Then, a designing method is introduced to improve the frequency response. After that, to survey three excitation modes three sets of the numerical values of capacitors and inductors are obtained so that three pass bands can be created by changing the values of the capacitors and inductors. Finally, using the proposed resonators a novel microstrip triplexer is presented and optimized.

\section{Design of diplexer}

Coupled lines loaded by microstrip cells and stubs are integrated to work as a resonator, as shown in Figure 1a. This basic structure will be used to design a compact triplexer. An $L C$ model for the coupled lines is selected based on the proposed model in [22, 23]. The equivalent $L C$ circuit of the introduced resonator is shown in Figure $1 \mathrm{~b}$. In the $L C$ equivalent circuit, $L_{\mathrm{C}}$ demonstrates the coupling between coupled lines. Furthermore, the equivalent model of half line includes $L_{\mathrm{e}}$ and $C_{\mathrm{e}}$. The $L C$ model of stub1 is replaced by the inductor and capacitor $L_{1}$ and $C_{1}$. Accordingly, stub1 can be a step impedance cell while $C_{1}$ and $L_{1}$ are related to the wider and thinner parts respectively. Similarly, we assume stub 2 is another step impedance cell which its $L C$ model includes the capacitor and inductor $C_{2}$ and $L_{2}$.

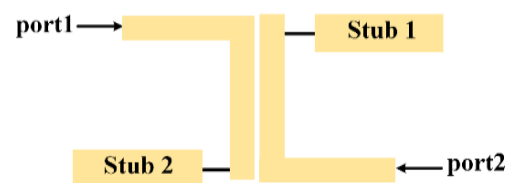

(a)

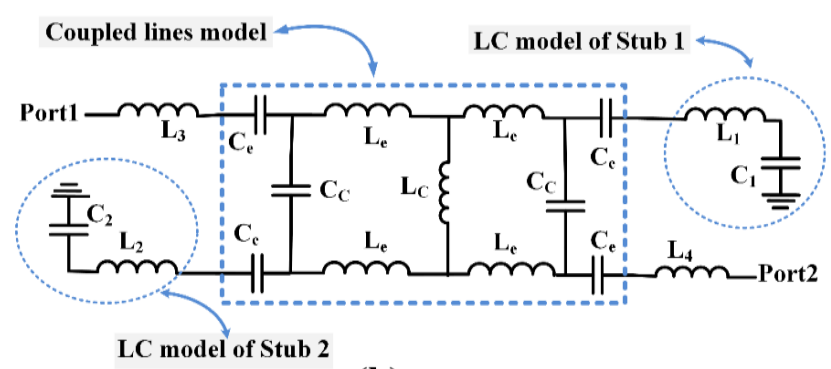

(b)

Figure 1. Presented resonator (a) layout (b) LC equivalent circuit.

Since the effect of the bents and steps in widths is considerable at the frequencies greater than $10 \mathrm{GHz}$, in the case of our design their effects are unimportant. Therefore, our proposed $L C$ circuit is an approximated model. The transmission lines connected to port1 and port2 have inductance features as depicted by inductors $L_{3}$ and $L_{4}$ respectively [24]. We simulated the $L C$ equivalent circuit of the proposed resonators for different values of the inductors and capacitors. As shown in Table 1, three sets of the numerical values of the capacitors and inductors are obtained to resonance at the requested frequencies of $3.6 \mathrm{GHz}, 3.2 \mathrm{GHz}$ and 2.3 GHz. The results of the introduced resonator are depicted in Figure 2.

From the numerical data, the impedance of each section $Z_{c}$ can be calculated. By selecting a dielectric constant of 2.2 and having the calculated impedances of each section, we can calculate the ratio $\mathrm{w} / \mathrm{h}$ for each microstrip cell using the following equation [24]: 
Table 1. Numerical values for the equivalent LC model of the introduced resonator.

\begin{tabular}{|l|c|c|c|c|c|c|c|c|c|c|}
\hline & $\begin{array}{c}\boldsymbol{L}_{\mathbf{e}} \\
(\mathbf{n H})\end{array}$ & $\begin{array}{c}\boldsymbol{L}_{\mathbf{c}} \\
(\mathbf{n H})\end{array}$ & $\begin{array}{c}\boldsymbol{L}_{\mathbf{1}} \\
(\mathbf{n H})\end{array}$ & $\begin{array}{c}\boldsymbol{L}_{\mathbf{2}} \\
(\mathbf{n H})\end{array}$ & $\begin{array}{c}\boldsymbol{L}_{3} \\
(\mathbf{n H})\end{array}$ & $\begin{array}{c}\boldsymbol{L}_{\mathbf{4}} \\
(\mathbf{n H})\end{array}$ & $\begin{array}{c}\boldsymbol{C}_{\mathbf{C}} \\
(\mathbf{p F})\end{array}$ & $\begin{array}{c}\boldsymbol{C}_{\mathbf{e}} \\
(\mathbf{p F})\end{array}$ & $\begin{array}{c}\boldsymbol{C}_{\mathbf{1}} \\
(\mathbf{p F})\end{array}$ & $\begin{array}{c}\boldsymbol{C}_{\mathbf{2}} \\
(\mathbf{p F})\end{array}$ \\
\hline Resonance at 3.61 GHz & 0.5 & 6 & 2.5 & 0.56 & 0.5 & 1.6 & 4 & 2 & 0.5 & 3 \\
\hline Resonance at 3.2 GHz & 0.5 & 6 & 2.5 & 10 & 0.5 & 1.6 & 22 & 2 & 2 & 3 \\
\hline Resonance at $\mathbf{2 . 3} \mathbf{G H z}$ & 1 & 0.2 & 3.3 & 10 & 3.75 & 1.8 & 10 & 1 & 0.5 & 3 \\
\hline
\end{tabular}

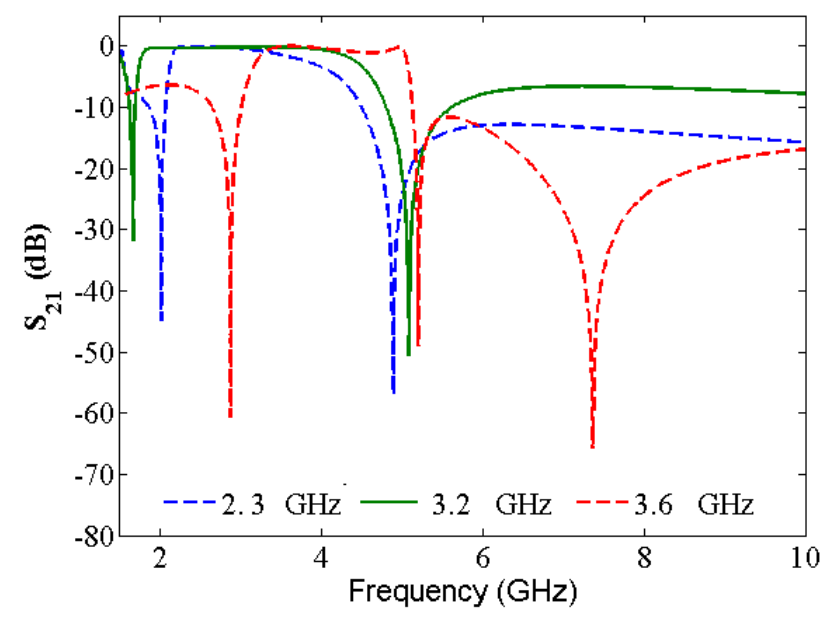

Figure 2. Simulation results of the proposed resonator for three sets of values in Table 1.

$$
\begin{aligned}
& \text { for } w / h \leq 1: \\
& \varepsilon_{r e}=\frac{\varepsilon_{r}+1}{2}+\frac{\varepsilon_{r}-1}{2}\left\{\left(1+12 \frac{h}{w}\right)^{-0.5}+0.04\left(1-\frac{w}{h}\right)^{2}\right\} \\
& Z c=\frac{\eta}{2 \pi \sqrt{\varepsilon_{r e}}} \ln \left(\frac{8 h}{w}+0.25 \frac{w}{h}\right) \\
& \text { for } w / h \geq 1: \\
& \varepsilon_{r e}=\frac{\varepsilon_{r}+1}{2}+\frac{\varepsilon_{r}-1}{2}\left(1+12 \frac{h}{w}\right)^{-0.5} \\
& Z c=\frac{\eta}{\sqrt{\varepsilon_{r e}}}\left\{\frac{w}{h}+1.393+0.677 \ln \left(\frac{w}{h}+1.444\right)\right\}^{-1}
\end{aligned}
$$

After achieving $\mathrm{w} / \mathrm{h}$ for each cell, the overall dimensions of microstrip cell will be obtained. According to this method, the shape and dimensions of the proposed resonator can be achieved. Using the proposed resonator a microstrip triplexer is realized as shown in Figure 3. There are four pairs of the coupled lines which one of them is added to integrate the resonators rather than as a resonator. T-shape taped line feed structures are utilized to improve the matching. The coupled lines at port3 are placed horizontally to reduce the size. 


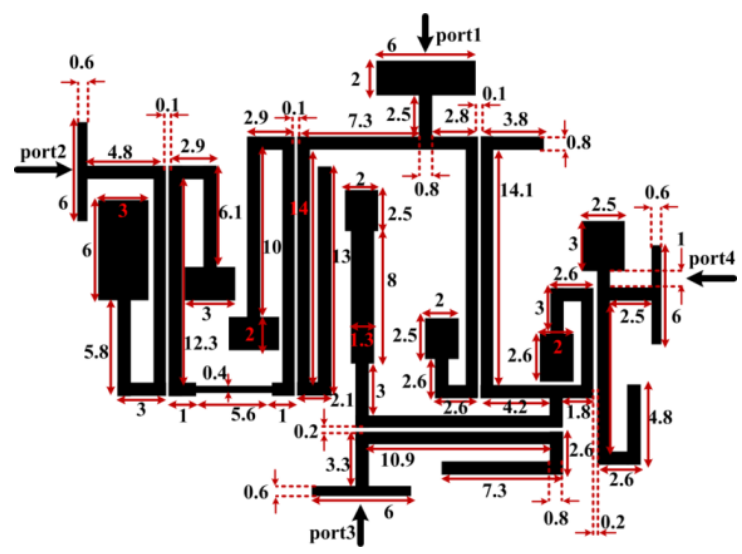

Figure 3. The proposed triplexer layout (dimensions are in millimeter).

\section{Results and discussion}

We used ADS (Advanced Design System) software for designing and simulation of the proposed microstrip triplexer. To fabricate the designed triplexer an RT/duroid5880 substrate with $\tan \delta=0.0009, h=31$ mil and $\varepsilon_{\mathrm{r}}=2.22$ is used. We used the N5230A network analyzer to measure the frequency responses. In Figure $4 \mathrm{a}$, the measured and simulated S-parameters, i.e., $S_{21}, S_{31}, S_{41}$ and $S_{11}$ are shown. From Figure 4 it is clear that the band widths are $120 \mathrm{MHz}$ (centered at $2.3 \mathrm{GHz}$ ), $180 \mathrm{MHz}$ (centered at $3.2 \mathrm{GHz}$ ) and $60 \mathrm{MHz}$ (centered at $3.6 \mathrm{GHz}$ ).
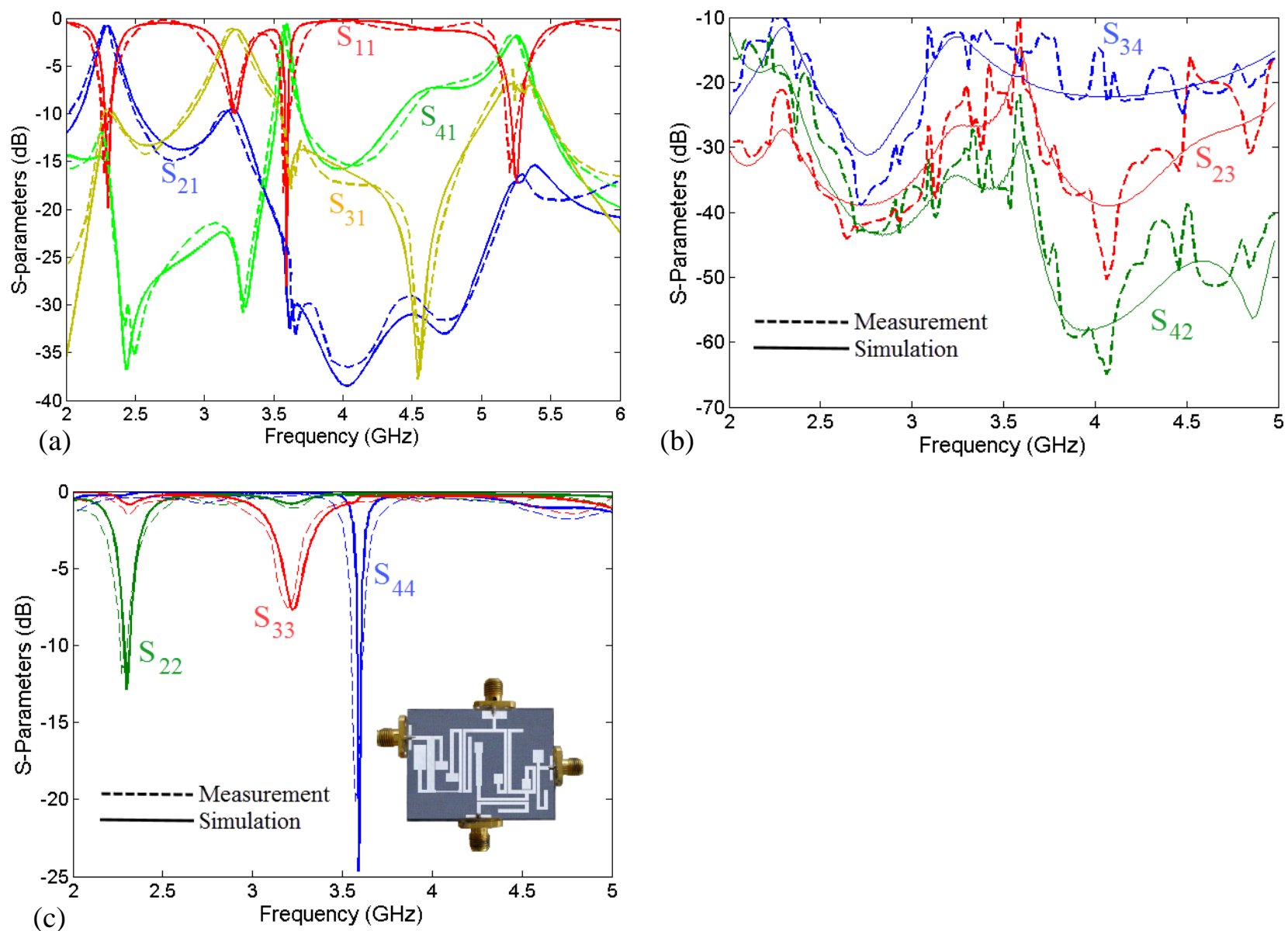

Figure 4. Measured and simulated (a) $S_{21}, S_{31}, S_{41}$ and $S_{11}$ (b)isolation between three ports (c) $S_{22}, S_{33}$ and $S_{44}$ and a photograph of the fabricated triplexer. 
Also, the diplexer has low insertion losses $(0.78 \mathrm{~dB}, 1.19 \mathrm{~dB}$ and $0.62 \mathrm{~dB})$ at the center resonance frequencies. Also, the return losses of the input port at $2.3 \mathrm{GHz}, 3.2 \mathrm{GHz}$ and $3.6 \mathrm{GHz}$ are $19.8 \mathrm{~dB}, 10 \mathrm{~dB}$ and $28 \mathrm{~dB}$ respectively. Figure $4 \mathrm{~b}$ shows $S_{23}, S_{34}$ and $S_{42}$. The important isolation values at the resonance frequencies are listed in Table 2. The photograph of the fabricated diplexer and return losses from ports 1, 2 and $3\left(S_{22}, S_{33}\right.$ and $\left.S_{44}\right)$ are presented in Figure $4 \mathrm{c}$, where $S_{22}$ is $-12.88 \mathrm{~dB}$ at $2.3 \mathrm{GHz}, S_{33}$ is $-7.67 \mathrm{~dB}$ at 3.2 $\mathrm{GHz}$ and $S_{44}$ is $-24.67 \mathrm{~dB}$ at $3.6 \mathrm{GHz}$. The size of the introduced triplexer is $35.1 \mathrm{~mm} \times 26.1 \mathrm{~mm}$ or $0.35 \lambda_{\mathrm{g}} \times 0.26 \lambda_{\mathrm{g}}$, where $\lambda_{\mathrm{g}}$ is calculated at $2.3 \mathrm{GHz}$.

Table 2. Isolation at the resonance frequencies.

\begin{tabular}{|l|c|c|c|}
\hline & $\mathbf{2 . 3} \mathbf{~ G H z}$ & $\mathbf{3 . 2} \mathbf{~ G H z}$ & $\mathbf{3 . 6} \mathbf{~ G H z}$ \\
\hline $\boldsymbol{S}_{\mathbf{2 3}}(\mathbf{d B})$ & -17.85 & -34.57 & -29.66 \\
\hline $\boldsymbol{S}_{\mathbf{3 4}}(\mathbf{d B})$ & -11.47 & -13.18 & -19.24 \\
\hline $\boldsymbol{S}_{\mathbf{2 4}}(\mathbf{d B})$ & -27.29 & -27.24 & -14.87 \\
\hline
\end{tabular}

Table 3 illustrates the comparison with the previous works. Considering the information in the comparison table, relatively low insertion losses and compact circuit size are the strong points of the proposed triplexer, while the return losses and fractional band widths are acceptable. According to the obtained data, the maximum values of $S_{34}, S_{32}$ and $S_{24}$ from $2 \mathrm{GHz}$ up to $5 \mathrm{GHz}$ are $-11.47 \mathrm{~dB},-11.6 \mathrm{~dB}$ and $14.6 \mathrm{~dB}$ respectively. In comparison with references $[15,16]$ and $[20,21]$, our diplexer has smaller size. Also, it is better than reported diplexers in [16, 20-21] in term of insertion losses.

\section{Conclusion}

We presented a compact microstrip triplexer. The introduced triplexer is constructed by coupled lines and step impedance resonators for operating at $3.2 \mathrm{GHz}, 3.6 \mathrm{GHz}$ and $2.3 \mathrm{GHz}$ for WiMAX and wireless applications. We presented an $L C$ equivalent model of the introduced resonator and used it to tune the resonance frequencies. The proposed triplexer was compared with the previously reported designs. The obtained results showed that the introduced triplexer of a simple structure has a very compact size of 0.095 $\lambda_{\mathrm{g}}{ }^{2}\left(916 \mathrm{~mm}^{2}\right)$. Moreover, reasonable return losses and insertion losses are obtained at all pass bands.

Table 3. Comparison with the previous reported triplexers.

\begin{tabular}{|c|c|c|c|c|c|c|}
\hline Reference & $\begin{array}{l}f_{\mathrm{r} 1}, f_{\mathrm{r} 2}, f_{\mathrm{r} 3} \\
(\mathrm{GHz})^{*}\end{array}$ & $\begin{array}{l}\Delta 1, \Delta 2, \Delta 3^{* *} \\
(\%)\end{array}$ & $\begin{array}{l}\mathrm{IL}_{1}, \mathrm{IL}_{2}, \mathrm{IL}_{3}{ }^{* * * *} \\
(\mathrm{~dB})\end{array}$ & $\begin{array}{l}\mathbf{R L}_{1}, \mathbf{R L}_{2}, \\
\mathbf{R L}_{3}{ }^{* * * *}(\mathbf{d B})\end{array}$ & $\begin{array}{l}\text { Size } \\
\left(\mathbf{m m}^{2}\right)\end{array}$ & Size $\left(\lambda g^{2}\right)$ \\
\hline [1] & $0.9,2.45,5.35$ & $22,4,16$ & $0.37,0.68,0.4$ & $11.8,21.3,13.8$ & 4655 & 0.111 \\
\hline [2] & $3.2,3.7,4.4$ & $6.6,7.3,8.2$ & $2.7,2.5,1.8$ & $20,20,20$ & 414 & 0.136 \\
\hline [3] & $1,1.25,1.5$ & $4.6,6.3,3$ & $2.7,1.8,3.2$ & $16,16,16$ & 2513 & 0.064 \\
\hline [4] & $1.4,1.7,1.9$ & $4.9,4.5,4.8$ & $3.4,3.5,3.6$ & --- & 4871 & 0.358 \\
\hline [5] & $1.8,3.1,4.4$ & $7.4,7.4,6.2$ & $1.97,1.99,2.3$ & $24,22,25$ & 1122 & 0.177 \\
\hline [6] & $1.5,1.7,1.9$ & $3.3,2.9,2.6$ & $4.9,5.8,5.95$ & --- & 5304 & 0.132 \\
\hline [7] & $3.3,3.89,4.56$ & $16.2,13,16$ & $2.2,2.3,2.3$ & $14,14,14$ & 784 & 0.275 \\
\hline [8] & $2.15,3.95,3.8$ & $\begin{array}{ll}-- \\
\end{array}$ & $2.9,2.2,1.7$ & $20,20,20$ & 320 & 0.016 \\
\hline [9] & $2.05,2.45,3.5$ & $4.8,4,5.7$ & $1.5,1.8,1.5$ & $13,13,13$ & 4000 & 0.346 \\
\hline [10] & $1,2.4,5.8$ & --- & $0.8,2.1,2.5$ & $14.5,12,12.9$ & 2940 & --- \\
\hline [11] & $1.2,1.8,2.4$ & $14,14,13$ & $1.3,1.3,1.2$ & $11.6,14,10$ & --- & 0.055 \\
\hline [12] & $2.4,3.5,5.8$ & $6,4.5,3.6$ & $0.9,1.1,1.3$ & --- & 870 & 0.119 \\
\hline [13] & $0.9,2.4,5.5$ & --- & $0.7,1.7,1.5$ & --- & --- & --- \\
\hline [14] & $3.4,3.9,4.4$ & --- & From 1.6 to 2.2 & --- & 3180 & --- \\
\hline [15] & $2.67,3.1,3.43$ & --- & $0.72,0.63,0.71$ & $24.5,24,24.7$ & --- & 0.137 \\
\hline [16] & $2.4,3.5,5.2$ & --- & $2.42,1.62,1.95$ & less than 15 & --- & 0.164 \\
\hline [20] & $1.88,2.1,2.6$ & $0.86,1.4,0.96$ & $1.3,2.3,3.2$ & $22,25,21$ & --- & $>0.1$ \\
\hline [21] & $2.4,3.5,5.2$ & --- & $2.42,1.62,1.95$ & $>15$ & 1350 & 0.16 \\
\hline This work & $2.3,3.2,3.6$ & $5.2,5.5,1.6$ & $0.78,1.1,0.62$ & $19.8,10,28$ & 916 & 0.095 \\
\hline
\end{tabular}

$* f_{\mathrm{r} 1}, f_{\mathrm{r} 2}$ and $f_{\mathrm{r} 3}$ are the resonance frequencies (first, second and third, respectively).

** $\Delta_{i}(i=1,2,3)$ are the fractional bandwidths of the channel $i$.

$* * * \mathrm{IL}_{i}(i=1,2,3)$ are the insertion losses of the channel $i$. 
$* * * * \mathrm{RL}_{i}(i=1,2,3)$ are the return losses of the channel $i$.

\section{References}

[1] Zhu C., Zhou J., Wang Y., Design of microstrip planar triplexer for multimode/multi-band wireless systems, Microwave Journal, 2010 (2010), 1-19.

[2] Wu J.-Y., Hsu K.-W., Tseng Y.-H., Tu W.-H., High-Isolation Microstrip Triplexer Using MultipleMode Resonators, IEEE Microwave and Wireless Components Letters, 22(4) (2012), 173-175.

[3] Chen C.-F., Shen T.-M.,Huang T.-Y., Wu R.-B., Design of Multimode Net-Type Resonators and Their Applications to Filters and Multiplexers, IEEE Transactions on Microwave Theory and Techniques, 59(4) (2011), 848-856.

[4] Deng P-H., Lai M-I., Jeng Sh-K., Hsiung Ch., Design of Matching Circuits for Microstrip Triplexers Based on Stepped-Impedance Resonators, IEEE Transaction on Microwave Theory and Techniques, 54(12) (2006), 4185-4192.

[5] Chinig A., Errkik A., El Abdellaoui L., Tajmouati A., Design of a Microstrip Diplexer and Triplexer Using Open Loop Resonators, Journal of Microwaves, Optoelectronics and Electromagnetic Applications, 16(2) (2016), 65-80.

[6] Lin S.C., and Yeh C.Y., Design of Microstrip Triplexer with High Isolation Based on Parallel Coupled-Line Filters Using T-Shaped Short-Circuited Resonators, IEEE Microwave and Wireless Components Letters, 25(10) (2015), 648-650.

[7] CW T., Chen MG., Packaged microstrip triplexer with star-junction topology, Electronics Letters, 48(12) (2012), 699-701.

[8] Huang Y., Wen G. and Li J., Compact microstrip triplexer based on twist-modified asymmetric splitring resonators, Electronics Letters, 50(23) (2014), 1712-1713.

[9] Sugchai T., Nattapong I.and Apirun C., Design of Microstrip Triplexer Using Common Dual-mode Resonatorwith Multi-Spurious Mode Suppression for Multiband Applications, Applied Mechanics and Materials, 763 (2015), 182-188.

[10] Chen F-C., Qiu J-M., Hu H-T., Chu Q-X., and Lancaster M.J., Design of Microstrip LowpassBandpass Triplexer With High Isolation, IEEE Microwave and Wireless Components Letters, 25(12) (2015), 805-807.

[11] Jin X. and Yan Z., Microstrip triplexer and switchable triplexer using new impedance matching circuits, International Journal of RF and Microwave Computer-Aided Engineering, 27(1) (2016), 1-9.

[12] Wu H-W., Huang S-H. and Chen Y-F., Compact Microstrip Triplexer Based on Coupled Step Impedance Resonator, 2013 IEEE MTT-S International Microwave Symposium Digest (MTT), Seattle, WA, (2013), 1-3.

[13] Percaz J.M., Chudzik M., Arnedo I.,Arregui I., Teberio F., Laso M.A.G., and Lopetegi T., 2015. Producing and Exploiting Simultaneously the Forward and Backward Coupling in EBG-assisted Microstrip Coupled Lines, IEEE Antennas and Wireless Propagation Letters, 15, pp. 873-876.

[14] Karlsson M., Håkansson P., and Gong S., A Frequency Triplexer for Ultra-wideband Systems Utilizing Combined Broadside- and Edge-coupled Filters, IEEE Transaction On Advanced Packaging, 31(4) (2008), 794-801.

[15] Rezaei A., Noori L. Novel low-loss microstrip triplexer using coupled lines and step impedance cells for $4 G$ and WiMAX applications. Turkish Journal of Electrical Engineering \& Computer Sciences, 26 (2018), 1871-1880.

[16] Qian J.-F., Chen F.-C. Wide Stopband Microstrip Triplexer Using Common Crossed, Resonator and Uniform Impedance Resonator, Progress in Electromagnetics Research Letters, 69 (2017), 79-86. 
[17] Rezaei A., Yahya S.I., Moradi S., Jamaluddin M.H. A Compact Microstrip Triplexer with a Novel Structure Using Patch and Spiral Cells for Wireless Communication Applications, Progress In Electromagnetics Research Letters, 86 (2019), 73-81.

[18] Keshavarz S., Abdipour A., Mohammadi A., Keshavarz R. Design and implementation of low loss and compact microstrip triplexer using CSRR loaded coupled lines. International Journal of Electronics and Communications (AEÜ), 111 (2019), 1-5.

[19] Hsu H.-W., Tu W.-H. Microwave Microstrip Six-Channel Triplexer and Eight-Channel Quadruplexer, IEEE Transactions on Components, Packaging and Manufacturing Technology, 7(7) (2017), 1136 1143.

[20] Eltokhy A., Wu R., Wang Y., Microstrip Triplexer using a common triple-mode resonator. Microwave and Optical Technology Letters, 60 (7) (2018), 1815-1820.

[21] Qian J.-F., Chen F.-C. Wide Stopband Microstrip Triplexer Using Common Crossed Resonator and Uniform Impedance Resonator, Progress In Electromagnetics Research Letters, 69 (2017), 79-86.

[22] Williams L. and Kim S., Enhance the Design of LTCC RF Modules, MICROWAVES \& RF, 42(9) (2003), 90-96.

[23] Noori L. and Rezaei A., Design of a microstrip dual-frequency diplexer using microstrip cells analysis and coupled lines components, International Journal of Microwave and Wireless Technologies, 9(7) (2017), 1467-1471.

[24] Hong J.S. and M.J. Lancaster, Microstrip Filters for RF/Microwave Applications. John Wiley \& Sons, Inc., New York, 2001. 